\title{
二重拡散対流場中における垂直円筒周りの凝固過程に関する研究*
}

\author{
宮川 広康 ${ }^{* 1}$, 木村 繁男 ${ }^{* 2}$, 木綿 隆弘 ${ }^{* 3}$, 小松 信義 ${ }^{* 3}$
}

\section{Solidification process around a vertical cylinder in the presence of double diffusive convection}

\author{
Hiroyasu MIYAKAWA $^{* 1}$, Sigeo KIMURA ${ }^{* 2}$, Takahiro KIWATA ${ }^{* 3}$ and Nobuyoshi KOMATSU ${ }^{* 3}$ \\ ${ }^{* 1}$ Graduate School of Natural Science and Technology, Kanazawa University \\ Kakuma-machi, Kanazawa-shi, 920-1192, Japan
}

\begin{abstract}
We have conducted laboratory experiments of solidification on a cooling vertical cylinder in a hypoeutectic sodium nitrate solution that fills rectangular vessel, and formulated one-dimensional model for predicting the vertically averaged solid layer thickness. The experiments have been carried out by heating the lower wall of the vessel and cooling the vertical cylinder. Stratified concentration layers are formed in the vessel with the growth of solid due to the solute emission. As the process advances, the solution is eventually divided into two layers with a large density difference. The two layers have different average temperatures and concentrations. Taking the presence of the two layers into consideration, we have formulated the one-dimensional model for the growth of solid layer. The theoretical predictions compares well with the experimental results.
\end{abstract}

Key Words : Solidification, Binary aqueous solution, Vertical cylinder, Double diffusive convection, Concection stratification

\section{1. 精言}

地熱はエネルギ源の少ない日本にとって数少ない純国産のエネルギ源であり, 将来石油に代わるクリーンなエ ネルギとして期待される.さらに, 地下深くに存在するマグマ溜りまで採熱管を通し, 直接マグマから熱抽出を 行うマグマ発電というものも提案されており, 実現化されれば膨大な発電量の確保が期待されている(1). しかし, 地上の発電設備容量と採熱量とのバランスや採熱管の保護などの課題が存在し，これらの課題の解決のためマグ マのような多成分系の融液中において採熱管周りに形成される固相の厚さを制御する技術が必要とされる.

そこで本研究ではマグマ溜り中における分化過程の研究(2)(3)でよく使用される 2 成分系の水溶液を用いて, 矩形 水槽内に設置された冷却円筒まわりの凝固実験を行い，そこから得られた知見より固相厚さを予測する 1 次元の 数値モデルを定式化した. さらに 1 次元数值モデルの妥当性を検証するため実験值との比較を行った.

\section{2. 実験装置および方法}

本実験で用いた水槽の概略を図 1 に示す. 実験水槽は内径寸法が幅 $180 \mathrm{~mm} \times$ 奥行き $175 \mathrm{~mm} \times$ 高さ $180 \mathrm{~mm}$ の矩 形水槽である．側面および上面には厚さ $15 \mathrm{~mm}$ の透明なアクリル板を用い，下面には加熱用の銅板がはめ込まれ ている．また，上面の中心部には直径 $30 \mathrm{~mm}$ の穴が設けてあり，長さ $125 \mathrm{~mm}$ の銅円筒を挿入する構造となって いる. なお，上面には凝固時の体積増分を吸収するため，オーバーフロー管を設けてある. 供試流体には亜共晶 濃度の硝酸ナトリウム水溶液を用いており，その相平衡図を図 2 に示す．また，下面と銅円筒の内部には冷凍恒 温装置によって任意の温度に調節されたエチレングリコールと水の混合液を流し，それぞれの加熱，冷却を行う

\footnotetext{
*1 学生員, 金沢大学大学院自然科学研究科（广920-1192 石川県金沢市角間町）

*2 正員, フェロー，金沢大学環日本海域環境研究センター

*3 正員, 金沢大学理工学域機械工学系（T920-1192 石川県金沢市角間町）

E-mail: miyakawa@ryuko.ms.t.kanazawa-u.ac.jp
}

[No.12-1] 日本機械学会 2012 年度年次大会講演論文集 [2012.9.9-12, 金沢] 
ことができる. 熱電対は容器側面に垂直方向に 15 本, 円筒表面に 3 本, 下銅板に 1 本の計 19 本設置されており, それぞれ容器内垂直方向温度分布, 冷却面温度, 加熱面温度を測定する. また容器内濃度はマイクロシリンジを 容器側壁のシリコン部分に水平に挿入し，着目点の溶液を微量（約 $100 \mu \mathrm{d} ）$ 採取し，屈折率計を用いることによ り測定した．固相厚さはデジタルカメラを水槽の前に設置し，円筒部分を一定時閒閒隔で撮影し，測定した．な お，実験は $15^{\circ} \mathrm{C} に$ 保たれた恒温室内で行った。

本研究では加熱面温度を $0^{\circ} \mathrm{C}$, 冷却面温度を- $13^{\circ} \mathrm{C}$ と, 硝酸ナトリウム水溶液の初期濃度を(1) $12.5 \mathrm{wt} \%$, (2) $15.0 \mathrm{wt} \%$, (3) $17.5 \mathrm{wt} \%$ として実験を行った. また, 実験前に容器内の溶液を攪汼し, 容器内温度, 濃度を一様にし た後，円筒表面温度を降下させ，実験を開始した。実験は 24 時間行い，各種パラメータを測定した。

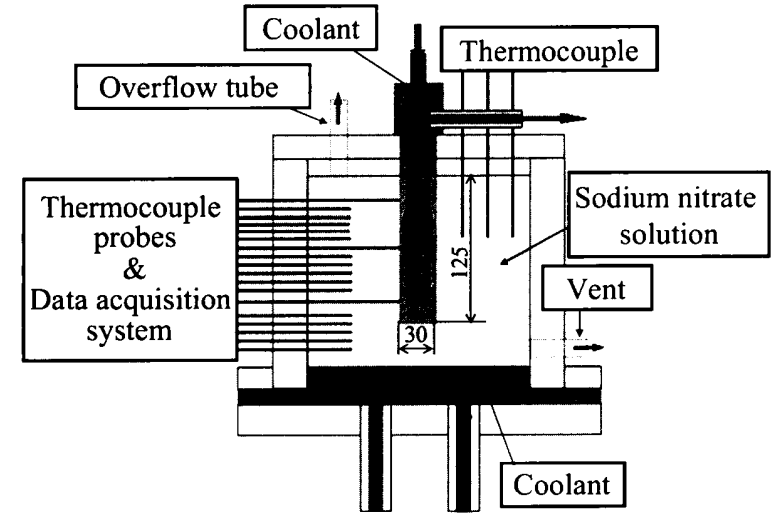

Fig.1 Experimental apparatus

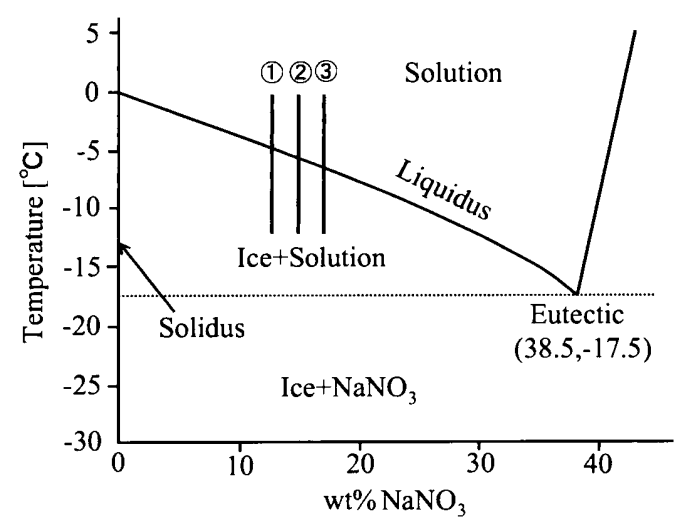

Fig.2 Phase equilibrium diagram for an aqueous solution of $\mathrm{NaNO}_{3}$

\section{3. 実験結果}

2成分系水溶液内における垂直円筒周りの凝固実験を行い，水槽内で起こる対流・拡散現象について実験を行 った. 使用した 2 成分系水溶液の溶質は硝酸ナトリウムであり, 垔共晶濃度で実験を行った. 水槽内で起こる現 象を時系列的に四 1 に示す. (a)に示すように凝固が始まるまで, 水槽内では熱対流のみが生じているが，(b)に示 すように固相が発生すると液相と固相の組成の違いのため, 固相から溶質の排出が起こる.そのため(c)に示寸よ うに時間の経過と共に底部に濃度が高い領域が形成され, 水平方向に長い対流が複数個生じる. それと同時に温 度分布も徐々に変化していき，底部と上部で温度差が拡がっていく，温度差による浮力が濃度差による浮力より 大きくなると小さな対流は結合し，大きな対流に変化していく．熱対流によってこの底部対流層の濃度が攪找さ れると, (d)に示すように上部との間に大きな濃度差を生じる.この層を密度跳躍層と呼ぶことにする. 密度跳躍 層は時間と共に上昇する傾向を示した. 図 4 と図 5 に各々, 実験条件(2)における密度跳躍層が生じた後の水槽内 温度分布, 濃度分布を示す. これらの図において縦軸は水槽内高さ, 横軸を温度, 濃度に採っている. 両図から わかるように密度跳躍層位置において温度, 濃度の值が大きく変化していることがわかる.

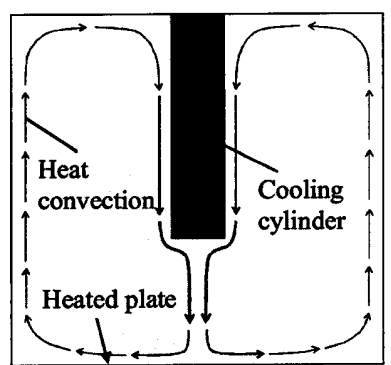

(a)

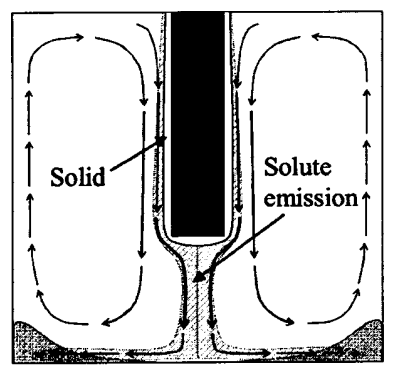

(b)

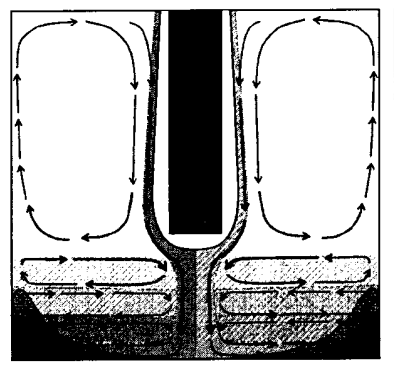

(c)

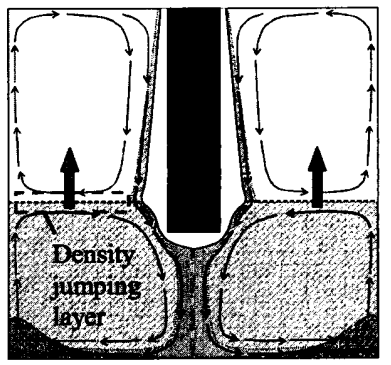

(d)

Fig.3 Appearance of experiment 
本研究では特に単成分系の液体の凝固と異なる点として以下の 3 つ点に注目した。第 1 は濃度排出と円筒周 囲の対流により固液界面近傍での濃度が変化し，融点を変動させること．第 2 は濃度排山により固相周囲を流れ る対流の浮力がより強くなり，固液界面への熱流束，また液相への質量流束を変化させること．第 3 は密度跳躍 層の上昇によって密度跳躍層の上下で発生する対流，そして各層に接する固相の厚さが変化することである. 固 相厚さの予測のために，これらの要素を考慮する必要がある.

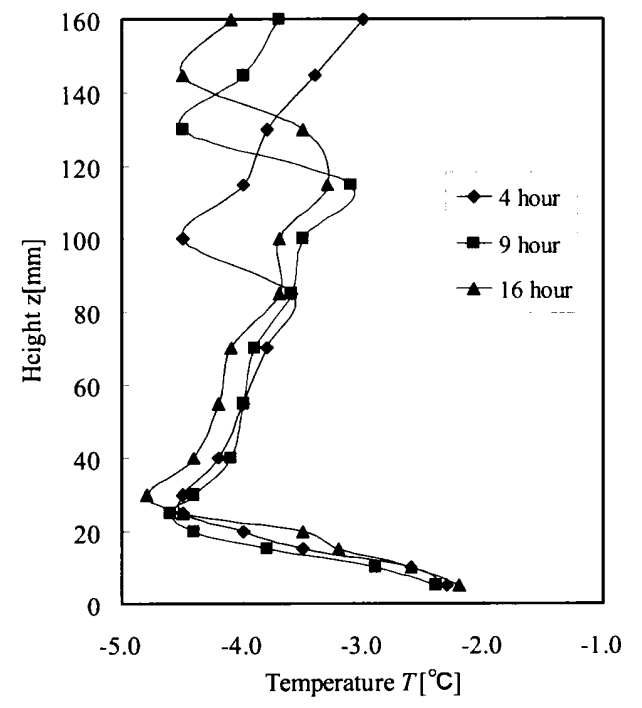

Fig.4 Temperature distribution in the vertical direction

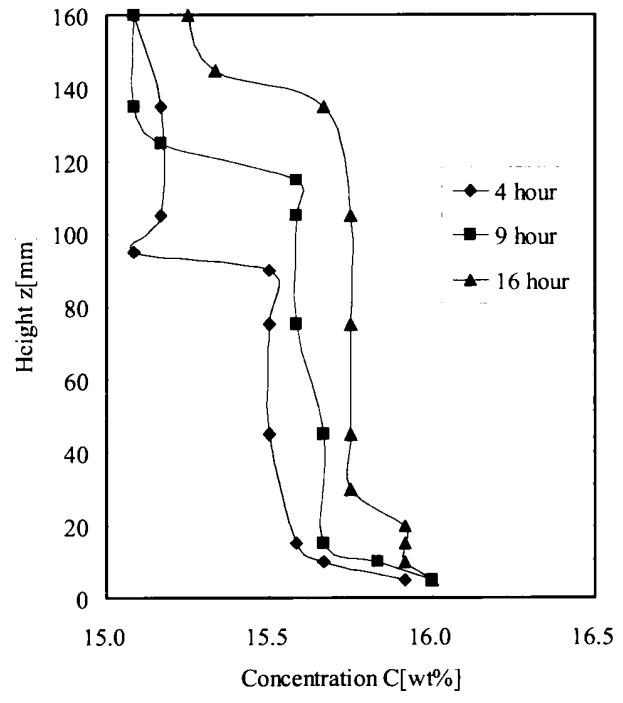

Fig.5 Concentration distribution in the vertical direction

\section{1 次元数値モデル}

本研究では 2 成分系水溶液内でおこる円筒周りの固相成長を予測するため, 円筒座標系における 1 次元モデル を仮定し，これを用いて数值解析を行った。1 次元数值モデルの概略を図 6 に示す.ここで冷却円筒の中心から 外向きにとった座標を $\mathrm{r}$ とし, 固相内鉛直方向の熱伝導を無視すると, 固相内と固液界面のエネルギ保存は以下 の 2 式となる.

$$
\begin{aligned}
& \frac{\partial T_{s}}{\partial t}=\alpha_{s}\left(\frac{\partial^{2} T_{s}}{\partial r^{2}}+\frac{1}{r} \frac{\partial T_{s}}{\partial r}\right) \\
& \frac{d f}{d t}=\frac{k_{s}}{\rho_{s} L}\left(\left.\frac{\partial T_{s}}{\partial r}\right|_{r=f}-\frac{q^{\prime \prime}}{k_{s}}\right)
\end{aligned}
$$

ここで $t$ は時間， $T$ は温度， $f$ は固液界面の位置， $\alpha$ は熱拡散率， $\rho$ は密度， $L$ は潜熱， $q$ " は液相から固液界面 への熱流束を示し，添え字"s"は固相を意味する。また固液界面上での濃度保存式は

$$
\frac{d C}{d t}=C \frac{d f}{d t}-\dot{m}
$$

となる.ここで $C$ は固液界面上での液相内濃度であり，第 1 項は固相成長に伴う溶質排出を示している． $\dot{m}$ は 固液界面上境界層内から液相への移流拡散による質量流束を示している。ここで計算された濃度から融点を次式 で求める.

$$
T_{i}=\left(\frac{d T}{d C}\right)_{\text {liquidus }}\left(C-C_{0}\right)+T_{0}
$$


ここで $T_{i}$ は融点温度， $(d C / d T)_{\text {liquidus }}$ は相平衡図から求まる液相線の傾き， $C_{0}, T_{0}$ はそれぞれ基準となる濃度 と温度を表している．また(2)式における液相からの対流による熱流束 $q^{\prime \prime}$ は次のように与えられる。

$$
q^{\prime \prime}=\frac{k}{H(h)} N u\left(T_{\infty}-T_{i}\right)
$$

ここで $H(h)$ は密度跳躍層位置 $h$ を変数とする代表長さ, $T_{\infty}$ は加熱面の温度, $N u$ は平均 Nusselt 数であり, 対 流の特徵を代表する Rayleigh 数や Prandtl 数, 円筒の代表長さの関数として表される(4). また濃度保存式(3)にお ける質量流束 $\dot{m}$ はエネルギ保存式と濃度保存式の相似性より $q^{\prime \prime}$ を利用して求めた.ここで Rayleigh 数は自然対 流における浮力の大きさを代表する無次元数であり, 次式のように与えられる.

$$
R a=g \frac{\beta_{T}\left(T_{\infty}-T_{i}\right)+\beta_{C}\left(C-C_{\infty}\right)}{\alpha_{l} v} H(h)^{3}
$$

$g$ は重力加速度, $\beta_{T}$ は液相の熱膨張率, $\beta_{C}$ は濃度増加による体積膨張率, $v$ は動粘度, $C_{\infty}$ は水槽内平均濃度 であり，添え字”l”は液相を意味する。このように固液界面上での液相濃度 $C$ が増加すると $R a$ は大きくなり, $q$ " や市を変化させる.

また密度跳躍層の成長を

$$
h=\frac{\sqrt{2}}{N_{s}}\left(\frac{g \alpha_{l} q^{\prime \prime}}{c_{l}} t\right)^{\frac{1}{2}}
$$

で与える.ここで $h$ は水槽底部から密度跳躍層までの高さ， $N_{s}$ はブラントーヴァイサラ振動数で濃度勾配から導 かれる安定成層の強度を表す振動数であり，cは比熱を示している.
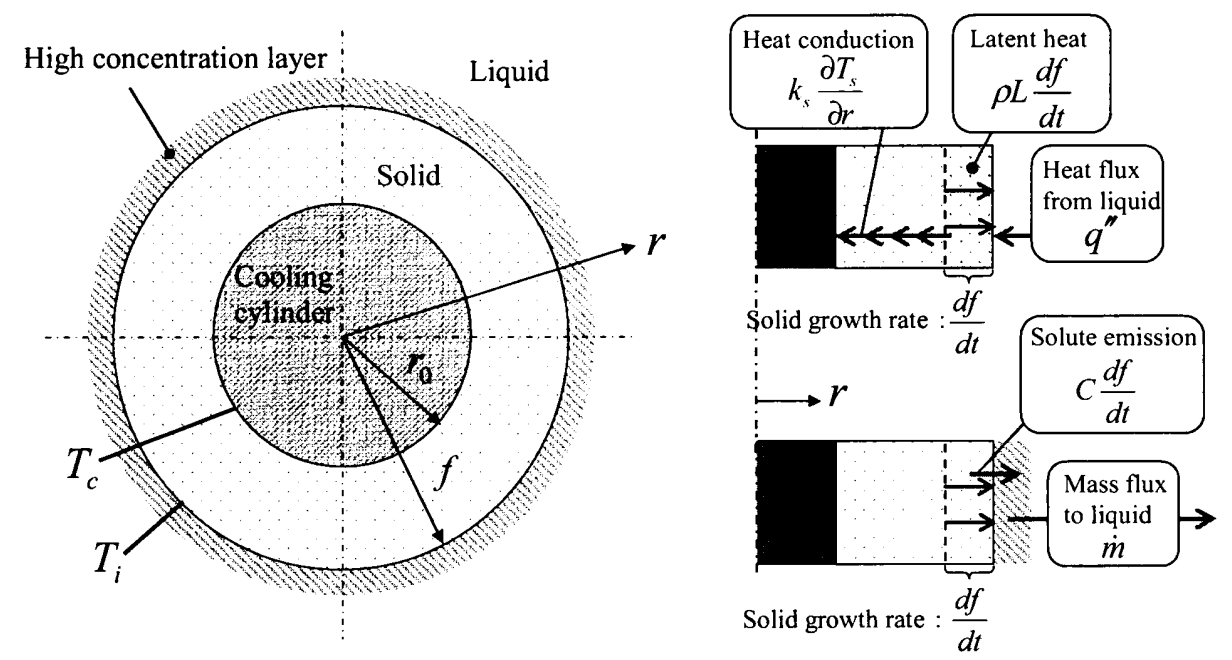

Fig.6 One-dimensional numerical model

\section{4. 実験結果と 1 次元数值モデルの比較}

上述した 1 次元数值モデルに基づき，数值計算した結果を以下に示す．図 7 は縌軸に鉛直方向に平均化した固 液界面位置，横軸に時間を採ったものであり，実験值と 1 次元モデルによる計算結果を同時にプロットした．図 7 における(a)，(b)，(c)はそれぞれ実験条件(1)，(2)，(3)に該当する．どの条件においても固相成長初期において計 算值は実験值より大きいが，定常状態に近づくにつれ計算值は実験值に近づいていくここの理由として固相成長 初期では, 図 3(c)に示した複数の対流が生じさせる複雑な熱伝達構造が界面熱流速の見積もりに大きな誤差を生 じさせたと考えられる. 密度跳躍層が発生すると対流が単一化し, 定常状態に近づくにつれ安定化することで, 熱流束の見積もりが正しい值に近づいたため，計算值は実験值に近づいていったと考えられる. 


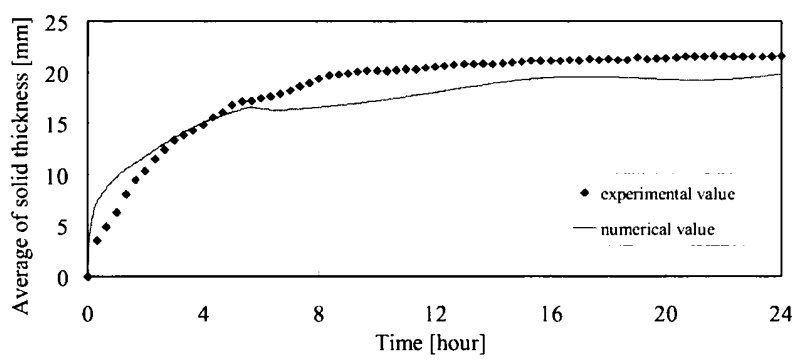

(a)

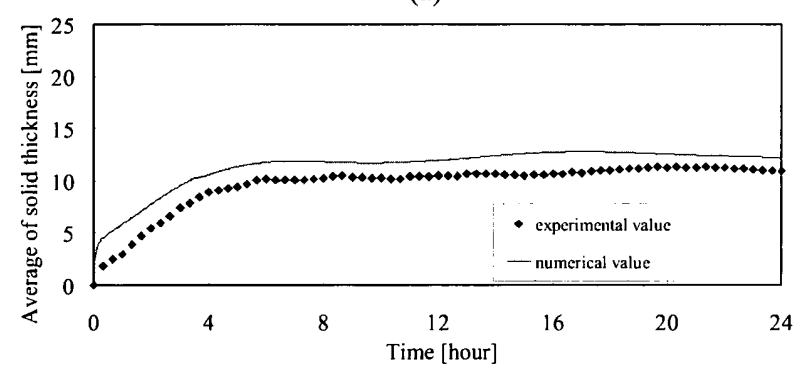

(c)

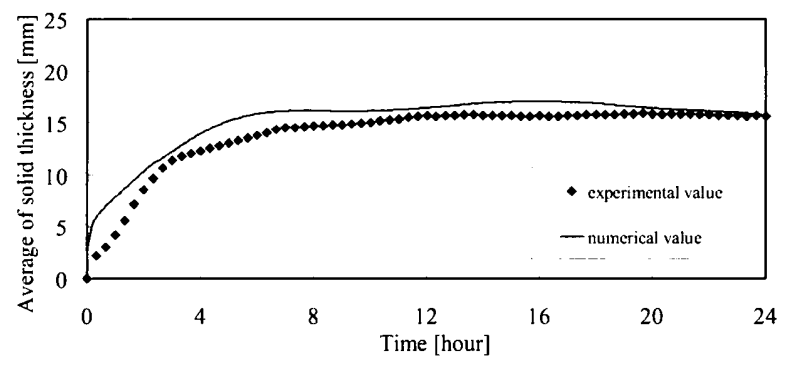

(b)

Fig7. Comparison between experimental and numerical results of solid layer growth

\section{4. 結言}

本研究では 2 成分系水溶液中における垂直円筒周りの凝固を対象とし，実験と 1 次元数值解析を行い，以下の 結論を得た。

(1) 固相成長による濃度排出と水槽底部からの熱供給により発生する密度跳躍層は水槽内の濃度分布, 洫度 分布に大きな影響を与える.

(2) 今回定式化した 1 次元数值モデルによって計算された結果は実験值とのある程度の一致を示し, 数值モ デルの妥当性を検証できた.

\section{文献}

(1) H. C. Hardee "Convective heat extraction from molten magma", Journal of Volcanology and Geothermal Research, 10 (1981), pp. 175-193.

(2) Herbert E. Huppert "Double-diffusive convection due to crystallization in magmas", Ann. Rev. Earth Planet. Sci., (1984), pp. 11-37.

(3) Herbert E. Huppert and J. Stewart Tumer "A laboratory model of a replenished magma chamber", Earth and Planetary Science Letters, 54 (1981), pp. 144-152.

(4) E. J. LeFevre and A. J. Ede, "Laminar free convection from the outer surface of a vertical circular cylinder", Proc. Ninth Int. Congr. Appl. Mech., Brussels, Vol. 4, 1956, pp. 175-183. 